\title{
Ovaryan dev kitlelere yaklaşım; jinekolojik, anestetik, patolojik yaklaşım; dört olgu sunumu
}

\author{
Alev Atış Aydın¹, Savaş Özdemir', Kaan Pakay', Ulufer Sivrikaya², Nedim Polat ${ }^{3}$, Nimet Göker ${ }^{1}$
}

\begin{abstract}
ÖZET:
Ovaryan dev kitlelere yaklaşım; jinekolojik, anestetik, patolojik yaklaşım; dört olgu sunumu

Ovaryan kitleler bazen dev boyutlara ulaşabilirler. Bu yüzden de diğer komşu organlara, büyük damarlara kompresyon uygulayıp patoloji yaratabilir, asit oluşturabilirler. Bu derece büyük kitlelerin çıkarılması sırasında çok fazla sıvı aspire edilmesine veya dev kitlenin çıkarılmasına bağlı olarak ciddi hipotansiyon ve Inferior Vena Cava (IVC) sendromu oluşabilir. Burada bu şekilde olan dört olguyu jinekolojik, patolojik, anestetik açılardan sunmak istedik.

Olgu: 54, 35, 39 ve 42 yaşında olan hastalar sırasıyla $20 \mathrm{~kg}$ ve $40 \times 20 \mathrm{~cm} ; 14 \mathrm{~kg}$ ve $40 \times 40 \times 40 \mathrm{~cm} ; 17$ $\mathrm{kg}$ ve $45 \times 50 \mathrm{~cm}$; ve $53 \times 50 \mathrm{~cm}$ kitle saptanıp opere edildiler. Histopatolojik tanıları sırasıyla ilk ikisi borderline müsinöz adenokarsinom, benign endometroid tümör ve son olarak müsinöz kistadenoma eşlik eden teratom şeklindeydi. Preoperatif değerlendirmede, hastaların aşırı abdominal distansiyona bağlı dispne ve taşipnesi vardı ve kan gazları hipoksikti. Supin hipotansiyon ve diğer major komplikasyonları önlemek için gerekli operatif tedbirler alınarak uygun anestezi tekniği ile opere edildiler. Major peroperatif ve postoperatif herhangi bir komplikasyon oluşmadı.

Tartışma: Dev kitle eksizyonları önemli morbidite ile beraber olabilirler. Bu genelde kitlenin büyüklüğüne ve hastanın kötü kondisyonlarına bağlıdır. Eğer operasyon için gerekli tedbirler alınmazsa dev kitleler kanama ve hipotansiyon, elektrolit bozuklukları ile beraber belirgin morbidite ve ciddi problemlere sebep olurlar. Bu yüzden ventilatörle monitorizasyon, hemodinamik değerlendirme, hipotermi ve koagülopati için uygun tedbirler alınıp operasyona multidisipliner hazırlanmalıdırlar.

Anahtar kelimeler: Dev adneksiyel kitle, anestezi, patoloji, yaklaşım
\end{abstract}

\section{ABSTRACT:}

Giant ovarian masses, gynecologic, anestetic and pathologic assessment; analysis of four cases

Ovarian masses sometimes can be seen as bulky masses reaching to huge amounts. Most pathologic signs can be attributed to compression effect on intraabdominal organs, vascular structures and ascites made by tumor. After removal of such huge pelvic masses, serious clinical hypotension and inferior vena cava (IVC) syndrome can be seen related to the aspiration of high levels of fluid or resection of bulky mass. Here, we present four cases of bulky ovarian masses by means of gynecologic surgery, anaesthesia and pathology.

Case: $54,35,39,42$ years old patients having $20 \mathrm{~kg}$ and $40 \times 20 \mathrm{~cm} ; 14 \mathrm{~kg}$ and $40 \times 40 \times 40 \mathrm{~cm}, 17 \mathrm{~kg}$ and $45 \times 50 \mathrm{~cm}$ and $53 \times 50 \mathrm{~cm}$ adnexal masses respectively were operated. Histopathologies were found each to be the first two borderline mucinous carcinomas, third one was benign endometrioid tumor and the fourth one was mucinous cystadenoma complexed with teratom structures. On preoperative assessment, patients had dyspnea and tachypnea due to huge abdominal distention, blood gas parameters were hypoxic. To prevent supin hypotensive syndrome and other complications peroperatively, cases were evaluated by anesthesiology and the appropriate anesthesia technique was chosen, no major complications were seen in the peroperative or postoperative periods.

Discussion: Giant ovarian cyst excision may be associated with significant mortality. Most of the problems are due to the size of the cyst and to the patient's poor condition. Serious problems in this case mainly develop because of intraoperative blood loss and duration of the operation, postoperative hypotension and electrolyte disorders may be seen. Special attention should be paid to ventilator monitoring and hemodynamic assessment peroperatively and intraoperative fluid imbalance, hypotermia and coagulopathy regulation and the operative approach in the planning area needs to be done carefully.

Key words: Giant ovarian mass, anesthesia, pathology, management

Ş.E.E.A.H. Tıp Bülteni 2013;47(1):35-40
'Dr., Şişli Etfal Eğitim ve Araştırma Hastanesi, 1. ve 3. Kadın Doğum Klinikleri, Şişli, ìstanbul-Türkiye

${ }^{2}$ Dr., Şişli Etfal Eğitim ve Araştırma Hastanesi, Anestezi Kliniği, Şişli, İstanbul-Türkiye ${ }^{3}$ Dr., Şişli Etfal Eğitim ve Araştırma Hastanesi, Patoloji Kliniği, İstanbul-Türkiye

Yazışma Adresi / Address reprint requests to: Dr. Alev Atış Aydın, Şişli Etfal Eğitim ve Araştırma Hastanesi, 1. ve 3. Kadın Doğum Klinikleri, Şişli, İstanbul-Türkiye

Telefon / Phone: +90-506-316-6706

E-posta / E-mail:

alevatis@mynet.com

Geliş tarihi / Date of receipt: 7 Ekim 2011 / October 7, 2011

Kabul tarihi / Date of acceptance: 23 Ocak 2012 / January 23, 2012 


\section{GíRiş}

Over kanserleri tüm kadın genital sistem kanserlerinin yaklaşık \%30'unu oluşturur. İnsan over kanserlerinin hemen hemen $\% 90$ ı overin yüzey epitelinden gelişir. Over karsinomları kadın genital sistem maligniteleri arasında en çok ölüme neden olur. Genelde belirti vermeyip sinsi ilerlerler veya bazen klinik olarak şaşırtıcı dev boyut ve hacime ulaşabilirler $(1,2)$. Boyutları çok büyük olduğunda tümörün sekresyonuna bağlı asit, karında şişlik ve bası bulguları oluşabilir hatta diyaframı geçip plevral efüzyona, hidrotoraksa neden olabilirler. Plevra sıvısı sağda daha sık olmakla birlikte, solda veya bilateral de olabilir. Pelvik tümörün çıkartılması ile asit ve plevra sıvısı genellikle iki hafta içinde iyileşir (3).

Benign over tümörlerinin \%25 kadarı müsinöz kistadenomlardır. Çift taraflı olma olasılıkları seröz kistadenomlara göre daha düşüktür ve habaset olasılığı azdır. Oluş mekanizması tam olarak bilinmemekle birlikte en çok kabul gören teori yumurtalıkların üzerini örten epitel hücrelerinin şekil değiştirerek rahim ağzının içini (serviks) döşeyen epitele dönmesi ve tıpkı rahim ağzında olduğu türde salgılamada bulunmasıdır. Başka bir teoriye göre de embriyonik dönemde barsakları oluşturan hücrelerin kalıntılarından köken almaktadır. İnsanda görülen en büyük kistik yapılardır. Müsinöz kistadenom genellikle genç kadınlarda gelişen bir tümördür Genelde 15-30 santimetre boyutlarında olabilirler ancak 60 santimetreye kadar büyümüş olan müsinöz kistadenomlar literatürde mevcuttur. Kist genellikle içindeki ince zarlar ile pekçok odacığa bölünmüştür. Kistin içerisinde berrak ancak akışkan olmayan mukoid bir sıvı bulunur $(4,5,6)$.

Dev ovaryan kitlelerin patolojik belirtileri, kan damarlarını da içeren intraabdominal organ ve yapılara basıya neden olan kitle etkisinden kaynaklanır. Büyük abdominal kitlesi olan hastaların büyük bir çoğunluğunda yüksek volümün aspirasyon ya da kitlenin rezeksiyonuna bağlı ciddi klinik hipotansiyon veya inferior vena cava (IVC) basısına IVC sendromu gelişir $(3,4)$. Burada dev ovarian kitleli dört hastanın operasyonuna cerrahi, anestetik ve patolojik yaklaşımı ve peroperatif gelişebilecek IVC sendromunu tedbirlerini sunmak istedik.

\section{OLGU 1}

54 yaşında, gravite 2, parite 2, son adet tarihi 18 ay önce olan hasta 45 gün içerisinde gelişen karın şişliği nedeniyle başvurduğu iç hastalıkları polikliniğinden jinekolojik malignite araştırması nedeniyle tarafımıza konsülte edildi. Hastanın başvuruda genel durumu iyi, boyu $155 \mathrm{~cm}$, kilosu 95 kg, kan basıncı 140/90 mmHg, nabız 76/dk. vücut ısısı 37,1 derece idi. Batında yaklaşık $40 \mathrm{~cm}$ 'lik kitle palpe edildi. Bilateral pretibial (+++) ödem mevcuttu. Bazalde solunum sesleri alınamadı. Çekilen PA akciğer filminde bilateral diafragma yüksekliği saptandı. Plevral efüzyon minimal/yok olarak değerlendirildi. Laboratuar incelemesinde hafif anemi $(\mathrm{Hb}: 11,1 \mathrm{~g} / \mathrm{dL})$ ve tümör marker yüksekliği (CEA: 67, CA 12.5:1230, AFP:101, CA15.3:64, CA 19.9: 7923 mIU) saptandı. Hastanın biokimya ve koagülasyon parametreleri normal saptandı. Ultrasonografide sağ adneksiyel alandan ksifoide kadar uzanan yaklaşık 40x25cm, yoğun içerikli kistik kitle, batında yaygın asit ve batın ön duvarında parietal peritonda diffüz olarak kalınlaşmış olup yer yer nodüler tarzda genişlemeler (omental kek ?) saptandı. Preoperatif tanı malign dev over kisti idi. Alınan asit mai aspirasyon sıvının incelemesi negatif olarak saptandı. Çekilen tüm batın BT'de; ksifoidden başlayıp tüm karnı işgal eden pelvise kadar uzanım gösteren solid komponentli geniş kistik kitle over orjinli olarak değerlendirildi. Kolonoskopide patolojik bir bulgu saptanmadı. Preoperatif olarak hastada konjestif kalp yetmezliği ve venöz obstruksiyon bul-

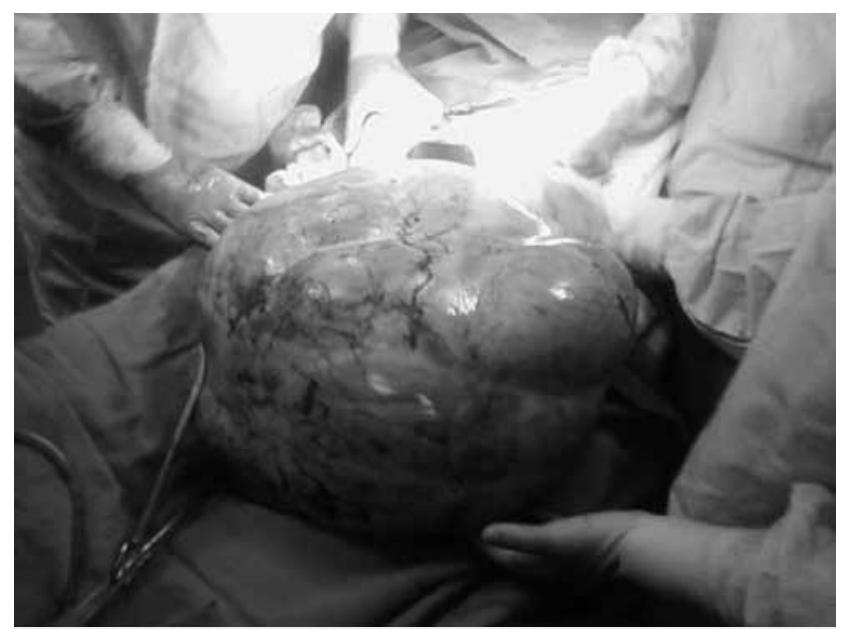

Resim 1: Illk olgunun peroperatif makroskopik görüntüsü 
guları saptanmadı. Hasta bu bulgularla operasyona alındı. Santral venöz basınç monitorize edildi. Laparotomide sağ overden kaynaklı, kapsülü intakt, 40×20 cm.boyutlarında 20 kg.ağırlığında heterojen kitle ve buna bağlı barsaklarda yapışıklık saptandı. Barsaklar kitle üzerinden künt disseksiyonla ayırıldı. Kitle ekstirpe edilip frozen için gönderildi, sonucun borderline over tümörü (müsinöz) olarak bildirilmesi üzerine hastaya total abdominal histerektomi+ bilateral salpingooferektomi + omentektomi+ apendektomi+ pelvik lenf nodu ve periton örneklemesi yapıldı (Resim 1). Operasyon esnasında hastada hipotansiyon, hipoksemi bulguları saptanmadı. Hasta elektrolit bozukluğu nedeni ile postop. yoğun bakıma alındı. Tedavisi düzenlenen hasta ertesi gün kliniğe alındı. Patolojisi; 'Borderline' Müsinöz Tümör (ekspansif paternde invazyon), lenf nodu negatif ve batın sIvıSı negatif olarak geldi. Daha sonraki takiplerinde yara yeri ekartasyonu gelişen hastaya sekonder sütür atıldı. Hasta postop 23.gününde onkoloji polikliniğine yönlendirilerek cerrahi şifa ile taburcu edildi.

\section{OLGU 2}

35 yaşında, gravite 4, parite 2, D\&C 2, düzenli adet gören ve son adet tarihi bir hafta önce olan hasta son 2 ay içinde gelişen karın şişliği nedeni ile iç hastalıklarında yaygın asit ve jinekolojik malignite düşünülmesi nedeniyle tarafımıza konsülte edildi. Hastanın başvuruda genel durumu iyi, TA:110/70mmHg, batın distandü idi ve bilateral pretibial (++) ödem saptandı. Ultrasonografi'de ksifoide kadar uzanan yaklaşık $25 \times 30 \mathrm{~cm}$, septasyonlar içeren, solid kistik alanlar bulunan kitle saptandı. Anamnezinde özellik bulunmayan hastanın laboratuar incelemesinde anemi (Hb:9,8 g/dL) saptandı. Tümör markerleri normal sınırlarda bulundu. Çekilen tüm batın BT'de; karaciğer orta kesim medialinden başlayıp mesane superiona kadar uzanan 20,5x29,5cm. septasyonlar ve solid komponenti de bulunan over orijinli malign tümör saptandı. Kolonoskopide 30cm'e kadar patoloji saptanmadı. Anestezi hazırlıkları tamamlandıktan sonra yoğun bakım şartları eşliğinde hasta operasyona alındı. Laparotomi yapıldıktan sonra $6000 \mathrm{~mL}$, yeşil kahve renkli sıvı yavaş bir hızla boşaltıldı. Laparotomi de sağ over kaynaklı, tüm batını dolduran 40x40x40cm, $14 \mathrm{~kg}$.

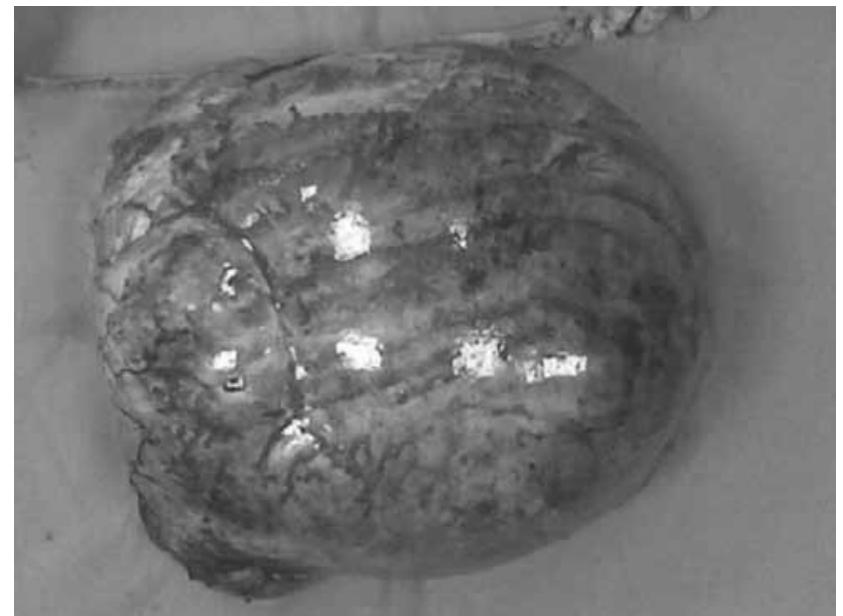

Resim 2: Borderline müsinöz kistadenomların histopatolojik görüntüsü (olgu 1 ve 2)

ağırlığında kistik solid alanları bulunan kitle izlendi (Resim 2). Kitle disseke edilip frozen için gönderildi, sonuç borderline müsinöz over tümörü olarak geldi. Operasyonda hipotansif seyreden ve elektrolit bozukluğu olan hasta postop yoğun bakıma alındı. Tedavisi düzenlenen hasta ertesi gün kliniğe alındı. Patolojisi; 'Borderline' ovaryan müsinöz tümör (intestinal tip) olarak geldi. Takiplerinde önemli problemi olmayan hasta postop 9. gününde cerrahi şifa ile taburcu edildi.

\section{OLGU 3}

37y GOPO, infertil hasta, polikliniğimize karın ağrısı, çocuk isteği şikayeti ile başvurdu. Ultrasonda

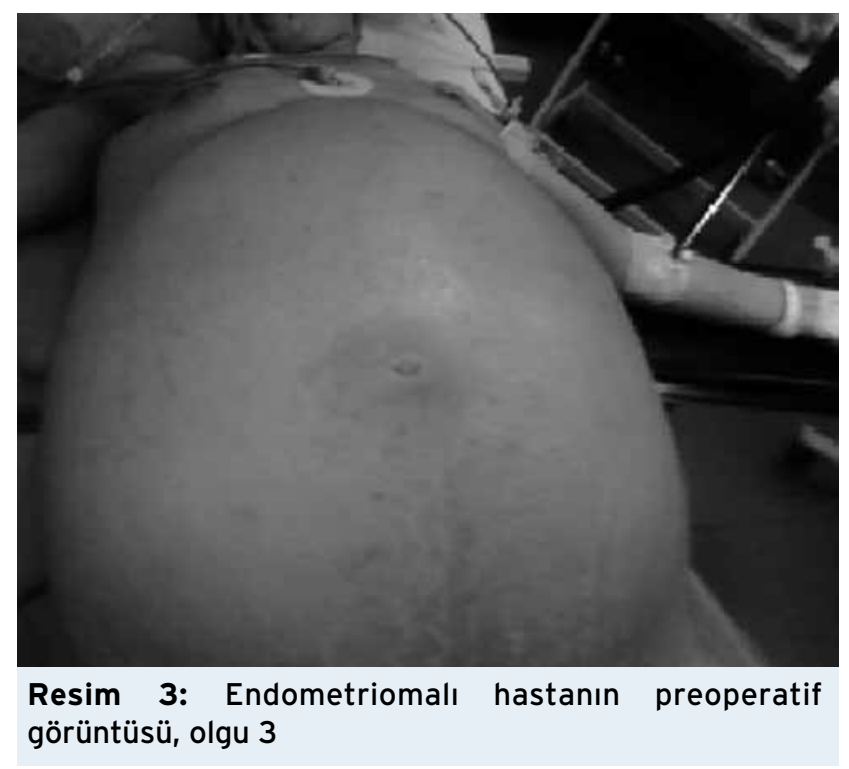



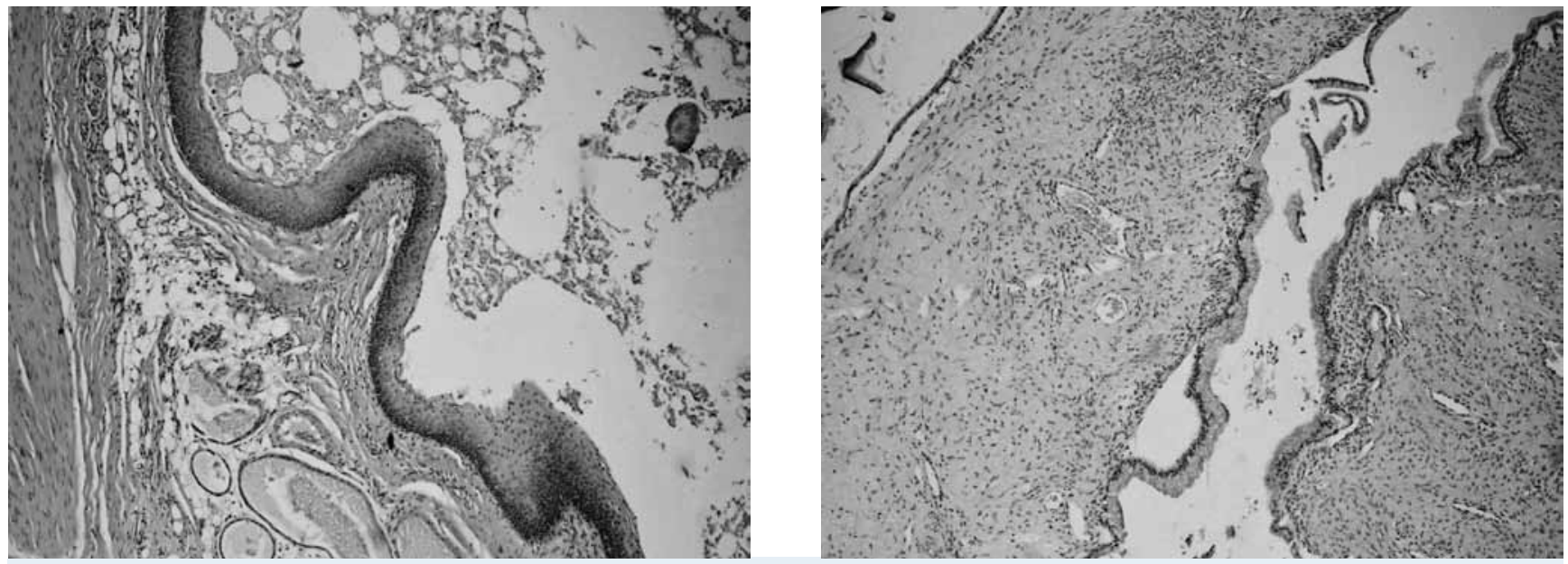

Resim 4: Dördüncü Olgunun histopatolojik görüntüsü 4a teratom komponenti ve 4b müsinöz komponenti

bütün batını dolduran kistik kitle saptandı. Asit saptanmadı ve Ca12-5:55 idi. Preoperatif hazırlıkları takiben küçük midline insizyonla batın açıldığında dev 30x40 $\mathrm{cm}$ boyutlarında kistik kitle gözlendi. Morbid obez olan hastada insizyonu çok genişletmemek için kist içeriği örneklendikten sonra aspiratörle yavaşça boşaltılıp kist cidarına ulaşıldı. Koyu renkli, çikolata kıvamında yaklaşık 3000cc mai boşaltıldı, Ardından kistektomiye geçildi. Frozen:benign endometroid tümör olması üzerine operasyona son verildi (Resim 3). Postoperatif herhangi bir komplikasyonla karşılaşılmadı.

\section{OLGU 4}

37y, G0 P0 virgo hasta, karın ağrısı şikayetiyle başvurdu.Ultrasonda solid-kistik alanlar içeren $40 \mathrm{~cm}$ kitle saptandı. CA-125:21.3, CA19-9:369.5, CA153:1.2 idi. Tumör marker yüksekliği ve solid-kistik olması nedeni ile gerekli hazırlıkları takiben midline insizyonla batın açıldığında 35×40 cm boyutlarında solid-kistik kıvamda kitle çıkarıldı. Frozen: benign olması nedeniyle, ooforektomi yapılıp operasyona son verildi. Patoloj: bir tarafında matur kistik teratom odağı olan müsinöz kistadenom olarak tespit edildi (Resim 4).

\section{TARTIŞMA}

Müsinöz kistadenomlar, insanda görülen en büyük kistik yapılardır (4-7). Çok büyük oldukları için rüptüre olma olasılıkları yüksektir. Böyle bir durum söz konusu olduğunda kist içinden yayılan sıvı karın boşluğuna yayılır ve hücreler burada da salgılarını sürdürür. Karnın içi yavaş yavaş jel gibi bir sıvı ile dolar. Biolojik olarak habis olmamasına rağmen davranış olarak habis bir olay olan bu tabloya pseudomiksoma peritonei adı verilir. Dev over kistleri diagnostik görüntüleme modalitelerinin yaygın olarak kullanımı ile birlikte nadir olarak bildirilmiştir. Daha önce bildirilen en geniş (büyük) tümör 149 kg. ağırlığında ve 1905'te Spohn tarafından çıkarılmıştır (8). Symmonds ve ark. 90-136 kg. arasında değişen dokuz over kisti bildirmiştir ve bunlar bazı hastalarda ölüme sebep olmuştur (9). Dolan ve ark. yakın zamanda, ağırlıkları 20-30 kg.'dan az laparoskopik olarak yönetilen dev over kistlerini bildirmiştir (10).

Supin hipotansif sendrom inferior vena cavadaki değişen derecelerdeki basıya bağlı olarak gelişen gebe kadınlarda ve dev abdominal kitleli hastalarda bildirilmiştir. Bütün vakalarda patolojik prosesi açıklamaya yardımcı olacak çeşitli klinik indikatörler mevcuttur, periferal ödem, dispne, ortopne, azalmış egzersiz toleransı, abdominal gerginlik, hipotansiyon, oligüride kötüleşme ve artmış jugüler basınç gibidir. Subklinik IVC sendromu over kistinden başka ek olarak karaciğer ve böbrek kisti olan insanların çoğunda gelişebilir. Bu sendrom bazen primer olarak uygun intravasküler volüm ve sempatik sistemin devreye girmesiyle oluşan hemostatik mekanizmalarla kompanse edilir. Konjestif kalp hastalığının karakteristik bulgu ve belirtilerinin yokluğu potansiyel olarak 
hemodinamik önemli IVC sendromunu ekarte ettirmez. Bu mekanizmalar (kompansasyon mekanizmaları) bozulduğunda, tam olarak kompansasyon olmayabilir ve azalmış venöz dönüşün belirtileri belirginleşebilir (11-15).

illk iki olgumuzda günümüzdeki en geniş ovarian kitlelerden 14 ve 20 kg. ağırlığındaki iki 'borderline' müsinöz ovarian kisti saptadık. Olgu 2'de artmış intraabdominal basınç kardiak ve respiratuar fonksiyonları etkiledi ve IVC ve aortaya basıya sekonder olarak supin hipotansiyona sebep oldu.

Her olgu preoperatuar dönemde anestezi tarafından değerlendirilip, uygulanacak anestezi yöntemi önceden belirlendi, postoperatuar dönem için Cerrahi Yoğun bakım Ünitesinde yer ayarlandı, oluşabilecek kan kayıplarında replasmanda kullanılmak üzere kan bankasında cross match eşleşmeleri uygun kan ve kan ürünleri rezervasyonları yapıldı. Genel anestezi uygulanan olgularda peroperatuar dönemde monitorizasyon radyal arter kateterizasyonu ile invaziv arteryel sistolik, diastolik, ortalama kan basınçları, kalp tepe atımı, periferik oksijen satürasyonu, idrar çıkışı takibini sağlayacak şekilde yapılmış olup birinci olguda daha radikal bir girişim planlandığından santral venöz basınç takibi için subklavyen ven kateterizasyonu uygulandı. Peroperatuar bir saat aralıklarla hemogram, kan şekeri, üre, kreatinin, elektrolit takibi ile arter kan gazı analizi değerlendirmeleri yapıldı. Birinci olguda daha belirgin olmak üzere her iki olguda da peroperatuar gelişen hipotansiyonun tedavisinde (başlangıç SAB değerine göre \%30'dan daha fazla azalma olması durumu) dopamin infüzyon tedavisi uygulandı. Birinci olguda Ca ve $\mathrm{K}$ düşüklüğü saptanıp, replasman tedavisi uygulandı. Klinik protokolümüz gereği 500 ml üzerinde kanama olduğu için kolloid ve kristaloid replasmanına ek olarak kan transfüzyonu da yapıldı. Peroperatuar ve postoperatuar dönemde kristaloid ve kolloid replasmanı yanı sıra, kan ve kan ürünleri transfüze edildi. Peroperatuar dönemde başlanan dopamin infüzyonuna postoperatuar olarak devam edildi. Yakın takip ve gerektiğinde tedavi edilebilmesi için olgular Postoperatuar Cerrahi Yoğun Bakım Ünitesi'ne alındılar, 36-48 saat içinde de durumlarının stabil seyretmesi sonrası Kadın Hastalıkları ve Doğum Kliniği'ne devredildiler.

Genel anestezi altında endojen sempatik aktivite azalır, bu da semptomatik IVC sendromuna ve hipoksemiye sebep olabilir. Dev abdominal kiste ek olarak pozitif basınçlı ventilasyonda göğüs ve abdomenden dönen venöz dönüşün azalmasına katkıda bulunabilir. Epidural anesteziyi tavsiye edilmemektedir Bu olgularda kistin kitle etkisine bağlı olarak gelişen venöz dönüşün azalmasını önlemek için subklavyan kateterizasyon uygulandı. Başarılı sonuç elde edilmesinde perioperatif volüm durumuna dikkat gösterilmesi büyük derecede katkı sağlandı. Üçüncü kitle tamamen kistik olup hasta morbid obezdi. Genel anestezi ve endotrakeal entübasyondan sonra, küçük bir insizyonla önce kistik kitle ponksiyone edilerek $3000 \mathrm{ml}$ seröz sıvı yavaş bir şekilde $(1000 \mathrm{ml} / \mathrm{dk}$.) boşaltıldı daha sonra kist cidarına ulaşıldı Bu olgular IVC basısının klinik ve radyolojik kanıtı olmasa da, perioperatif sıvı dengesizliğinin optimize edilmesinin ve venöz dönüşün maksimize edilmesinin önemini göstermektedir.

Epitelyal over tümörlerinin \%15'i borderline (düşük malign potansiyelli) over tümörleridir. Düşük malign potansiyelli over tümörleri yavaş bir büyüme hızına ve düşük invazif potansiyele sahiptir. Bu tümörler daha çok genç kadınlarda olmaya eğilimlidir ve sıklıkla invazif tümöre göre daha erken saptanırlar. Özellikle erken evrelerde prognoz mükemmeldir. Borderline over tümörlerinde prognoz çok iyi olduğu için ve gençlerde olmaya eğilimli oldukları için fertilite koruyucu konservatif yaklaşımlar tercih edilir (16-18). Hatta bazı otörler, konservatif yaklaşım ve endoskopik cerrahi planlarlar. Biz de genç olan düşük malign potansiyelli hastalarımız için konservatif cerrahi uyguladık.

Endometriozis reprodüktif yaş grubunda sık olan genellikle pelvik organları tutan bir infertilite ile ilişkisi olan hastalıktır. Endometriyotik kistler sıklıkla over dokusuna yerleşip endometrioma adını alırlar. Endometrioma zemininden over kanseri gelişebilir. Bu özellikle kistin büyüklügüne ve hastanın yaşına bağlıdır. Bir araştırmada 40 yaş sonrası hastalarda, 5 cm.' in altındaki kistlerde habis tümör olasılığı \%1 ve altında, 5-10 cm. arasında kitlelerin \%11'inde ve 10 $\mathrm{cm}$.in üzerinde \%72 habis tümör sıklığı bildirilmiştir. Zanetta ve ark.endometriozisden kanser gelişiminde karşılanmamış östrojen, hiperöstrojenizm ve obezite ilişkisinden bahsetmiştir (19-21). Endometriozisden 
kaynaklanman tümörler çoğunlukla düşük malign potansiyellidir .Üçüncü olgumuz infertil olup endometriomanın bu kadar dev boyuta ulaşmasının nedenini hastanın morbiz obez olması ve hiperöstrojenemi etkisi olarak düşündük ve çocuk istemi nedeniyle konservatif davrandık.

Son olgumuz ise literatürde nadir rastlanılan bir patolojiye sahipti. Matür kistik teratom zemininden kaynaklanan müsinöz kistadenomlar heterojen bir grup tümör olup tam histolojik spektrumları, ayrıntılı immünfenotipleri ve pseudomiksoma peritonei ile ilişkileri detaylı çalışılmamıştır. Genelde tek taraflı olup teratom komponentleri sıklıkla matürdür (2223). Olgumuzda frozen matür teratom ve benign müsinöz komponenti birlikte olduğu için konzervatif

\section{KAYNAKLAR}

1. Greene $\mathrm{MH}$, lark JW, Blayney DW: The epidemiology of ovarian cancer. Semin Oncol 1984;11:209.

2. Heint APM, Hacker NF, Lagasse LD: Epidemiology and etiology of ovarian cancer: A review. Obstet Gynecol 1992;66:127.

3. Tagge DU, Baron Pl. Giant adrenal cyst: management and review of the literature. Am Surg 1997;63:744-746.

4. Soslow RA. Histologic subtypes of ovarian carcinoma: an overview. Int J Gynecol Pathol 2008;27:161-74.

5. Platt JS, Rogers SJ, Flynn EA, Taylor RR. Primary angiosarcoma of the ovary: A case report and reviewof the literature. Gynecol Oncol 1999;73:443-6.

6. Hart WR. Mucinous tumors of the ovary: a review. Int J Gynecol Pathol 2005;24:4-25.

7. Jones Dr, Vasilakis A, Pillai L, Timberlake GA. Giant, benign mucinous cystadenoma of the ovary: case study and literature review. Am Surg 1992;58:400-403.

8. Spohn AE. Multicystic ovarian tumor weighing 3281 b. Tex Med J 1905-1906;1:273-274.

9. Symmonds RE, Spraitz AF, Koelsche GA. Large ovarian tumor: report of a case. Obstet Gynecol 1963;23:473-477.

10. Dolan MS, Boulanger SC, Salameh JR. Laparoscopic management of giant ovarian cyst. JSLS 2006;10:254-256.

11. Haspels AA, Zuidema PJ.A giant ovarian cyst in a Javanese woman. Br Med J (Clin Res Ed) 1982;284:1410.

12. Morrison P, Morgan G. Removal of a giant ovarian cyst. Anaesthetic and intensive care management. Anaesthesia 1987;42:965-974.

13. Vipond MN, Michie HR, Herhman MJ, Herhman M. Management of a giant ovarian cyst. Br J Hosp Med 1991;45:313-314. davrandık.

Sonuç olarak dev over kist eksizyonu ciddi mortalite ile ilişkili olabilir. Ciddi kardiyovasküler, respiratuvar, dolaşımsal bozukluklardan dolayı sıkıntılı, hatta hayatı tehdit edici problemler yaratabilir. Çoğu problem kistin büyüklüğünden ve hastanın zayıf durumundan köken almaktadır. Bu olgularda esas intraoperatif problemler ciddi kan kaybından ve operasyonun süresinden kaynaklanabilir. Hemodinamik ve ventilatör monitorizasyonun peroperatif değerlendirilmesine özel ilgi gösterilmeli ve intraoperatif sıvı dengesinin düzenlenmesini ve operatif yaklaşımı da içine alan dikkatli bir planlamanın yapılması gerekmektedir. Başarılı yönetim, multidisipliner yaklaşımı gerektirmektedir.

14. Suntharasaj T, Sriwongpanich S, Sorapipat $C$. The Largest ovarian cyst in Songklanagarind Hospital: a case report. J Med Assoc Thai 1994;77:445-448.

15. Zamora-Garza M, Rizo J, Dominguez A. Giant ovarian cyst: case report. Am J Obstet Gynecol 1992;166:1247-1248.

16. Darai E, Teboul J, Walker F, Benifla JL, Meneux E, Guglielmina $J N$, et al.Epithelial ovarian carcinoma of low malignant potential. Eur J Obstet Gynecol Reprod Biol 1996;66:141-145.

17. Candiani M, Vasile C, Sgerzi MR, Nozza A, Maggi F, Maggi R. Borderline ovarian tumors: laparoscopic treatment. Clin Exp Obstet Gynecol 1999;26:39-43.

18. Seracchioli R, Venturoli S, Colombo FM,Govoni F, Missiroli $S$, Bagnoli A. Fertility and tumor recurrence rate after conservative laparoscopic management of young women with early-stage borderline ovarian tumors. Fertil Steril 2001;76: 999-1004.

19. Heaps JM, Nieberg RK, Berek JS. Malignant neoplasms arising in endometriosis. Obstet Gynecol 1990;75:1023-8.

20. Chen KTK. Endometrioid adenocarcinoma arising from colonic endometriosis mimicking primary colonic carcinoma. Int J Gynecol Pathol 2002;21:285-8.

21. Zanetta GM, Webb MJ, Li H, Keeney GL. Hyperestrogenism: a relevant risk factor for the development of cancer from endometriosis. Gynecol Oncol 2000;79:18-22.

22. Hwang JH, So KA, Modi G, Lee JK, Lee NW, Lee KW, Kim I. Borderline-like mucinous tumor arising in mature cystic teratoma of the ovary associated with pseudomyxoma peritonei Int J Gynecol Pathol 2009;28:376-80.

23. Mandal S, Kawatra V, Khurana N. Mucinous cystadenocarcinoma arising in mature cystic teratoma ovary and associated pseudomyxoma peritonei: report of a case. Arch Gynecol Obstet 2008;278:265-7. 